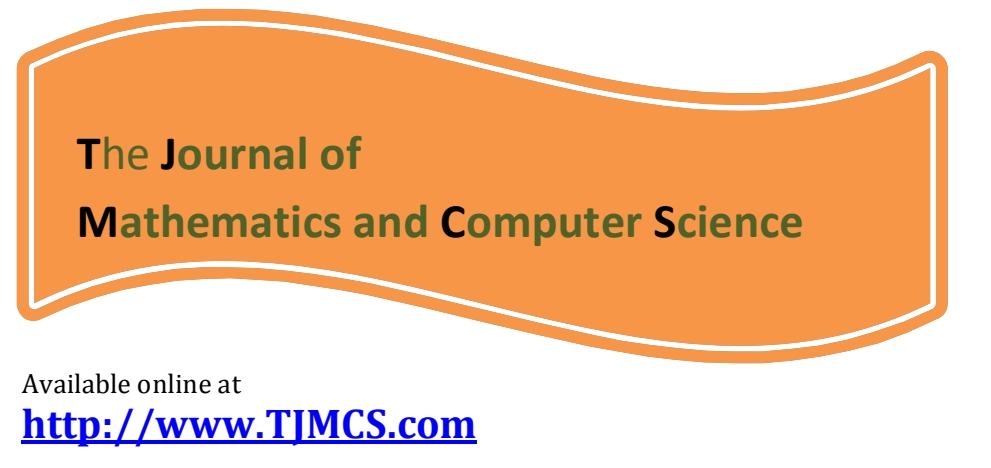

The Journal of Mathematics and Computer Science Vol. 4 No.3 (2012) 392 - 401

\title{
A Two Objective Model for Location-Allocation in a Supply Chain
}

\author{
AmirHossein Nobil $^{1}$, Abolfazl Kazemi ${ }^{2}$, Alireza Alinejad ${ }^{3}$ \\ ${ }^{1,2,3}$ Qazvin Branch, Islamic Azad University, Qazvin, Iran, \\ ${ }^{1}$ amirhossein.nobil@yahoo.com
}

Received: February 2012, Revised: May 2012

Online Publication: July 2012

\begin{abstract}
In today's competitive world, location-allocation (LA) decisions are one of the most important aspects of supply chain (SC) optimization. This LA decisions are including selection of known sites for construction of facilities and allocation of the distribution network between the levels of SC. In this paper, a nonlinear programming model to location facilities and allocate the supply chain distribution network in order to minimize both the cost and time of three-echelon are presented. The proposed model due to computational complexity in high dimensions cannot be solved with conventional and accurate methods, Therefore to achieve a solution of a method metaheuristic called genetic algorithm is used. Finally, to examine and the effectiveness of the proposed algorithm, computational results obtained are compared with output of lingo 12 software.
\end{abstract}

Keywords: Location-allocation; Supply chain; nonlinear programming; Genetic Algorithms

\section{1- Introduction}

In recent decades, many of which reduce costs due to location models have been considered by researchers [1]. Location theory by Fontan in 1826 was raised for the first time in agricultural activities [2]. But as formulated first by Alfred Weber [3] in 1909. His Location for a stock with the aim of minimizing the total distance traveled between warehouses and customers offered. Facility Location problems on site from among a set of known and constant. This problems for the construction of facilities such as hospitals, fire stations and emergency services are very useful.

In 1963, Cooper [4] developed the location problems. He said the first problems the facility Locationallocation. LA problem of effective decision making problem associated with the facility design. This problem, the optimal number and location of facilities according to distribution network and the objective function (maximum/ minimum) to be determined. 
In 1982, Murtagh and Niwattisyawong [5] proposed the capacitated facility location-allocation (FLA) problem, Unlike most previous done is that research is not without the capacity of the facility. Their model is considered to be one of the most important FLA researches focuses on capacity of facility.

In 1994, Liu and et al. [6] minimizing the total weighted distance from supply centers to customers with regard to the rectilinear distances, which is considered as one of the most important researches in this LA problems. In 2003, Liu and Zhou [7] proposed the stochastic model for LA problems with the capacity. In 2009, Bischoff and Dächert [8] compared to traditional search methods for LA problems with the new search methods and studied the effectiveness of these methods to each else.

In recent years, combined FLA problems with supply chain approach have been considered by researchers. Because of increasing customer expectations and industry competition, previous production management methods that focus on internal processes of the organization have lost their effectiveness and integrated supply chain approach is of interest to industrial managers. Supply chain is the communication between companies that create products and services directly and indirectly relate to each other [9] and these companies intend to work together to achieve their strategic objectives more efficient. In 2008, Ho and et al. [10] optimize the FLA problem in a customer-driven supply chain. This study of the analytic hierarchy process (AHP) and goal programming (GP) in order to maximize profits is used, considers both quantitative and qualitative factors. In 2011, Wang and et al. [11] presented LA decisions in the two-echelon supply chain with both profit and cost objectives. Their location decisions, which are related to with each other within the supply chain consists of three strategic decisions below stated.

* Locate facilities

* Distribution assignment

* Distribution quantity

Based on literature review studies, in regard to the attention of researchers has multiple objectives in most models. Also, those studies that was used of the multiple objective function is usually set up cost, shipping and profit in a two-echelon supply chain were in the real world is usually more than two echelon the supply chain is available. In this paper, an integer programming model for two-objective LA problem of minimizing the cost to set up factories, transportation, manufacturing, overtime and minimize production time in the supply chain is proposed. This model is presented in three echelons for supply chain suppliers, manufacturers, distributors. In this paper, the proposed model is solved using a metaheuristic method is called genetic algorithm. The proposed solution algorithm can near optimal solution for large-size as compared to a optimization tool called lingo.

This paper is organized as follows. Section 2, Modeling LA decisions will be described in order to minimize total costs and time. Section 3 is expressed by the genetic algorithm approach to solve the proposed model. Section 4 shows computational results and performance of the proposed algorithm. Finally, Section 5 concludes the study.

\section{2- The proposed model}

In this section, a mathematical model of two objectives LA to minimize total costs and time in threeechelon supply chain are presented. In this paper, LA problem is an integer nonlinear programming model. The model is the minimum set up cost, transportation, production, manufacturing, overtime, and also the production of goods in the supply chain. This supply chain consists of three levels of supplier, factory and distributor are linked together. This proposed model solves the following important decisions: 
How many sites should be selected for setting up the factory?

Which distribution centers should be connections with each factory?

Which factories should be connections with each supplier?

The notations of the location-allocation model in the supply chain are defined as following:

$D_{j}$ : Demand of distribution $\mathrm{j}$

$Q_{i}$ : Quantity of product produced in the factory $\mathrm{i}$

$f_{i}$ : Fixed cost of setting up a factory at site $\mathrm{i}$

$S_{i}$ : Capacity of factory located at site i

$G_{i}$ : Quantity of product in excess of production capacity in the factory $\mathrm{i}$

$U_{k}$ : Quantity of raw material produced in supplier i

$V_{i}$ : Production cost per unit product in factory i

$a_{i}$ : Production cost per unit product in excess of factory i capacity

$R_{k}$ : Production cost per unit raw material in supplier $\mathrm{k}$

$C_{i j}$ : Transportation cost per unit distributed from factory $\mathrm{i}$ to distribution $\mathrm{j}$

$B_{k i}:$ Transportation cost per unit delivered from supplier $\mathrm{k}$ to factory $\mathrm{i}$

$T_{i}$ : Production time per unit of product produced in factory $\mathrm{i}$

$L_{k}$ : Production time per unit of raw material produced in supplier $\mathrm{k}$

The decision variable is denoted as follows:

$x_{k i}$ : Configuration relationship between supplier and factory, $x_{k i} \in\{0,1\}$ where $x_{k i}=1$ if supplier $\mathrm{k}$ delivers raw materials to fulfill the demand to factory i, $x_{k i}=0$ otherwise.

$y_{i}$ : Decision to set up a factory, $y_{i} \in\{0,1\}$ where $y_{i}=1$ if a factory is set up at site i, $y_{i}=0$ otherwise.

$z_{i j}$ : Configuration relationship between factory and distribution, $z_{i j} \epsilon\{0,1\}$ where $z_{i j}=1$ if factory $\mathrm{i}$ distributes products to fulfill the demand to distribution $\mathrm{j}, z_{i j}=0$ otherwise.

In this model, the following assumptions are used: (1) there are a single period; (2) there is a single product and raw material; (3) there is three-echelon supply chain, supplier, factory and distribution; (4) supplier's capacity is unlimited; (5) factory's capacity is limited but can be compensated with overtime (6) a factory can serve several distribution while each distribution can be served only by a factory; (7) a supplier can serve several factory while each factory can be served only by a supplier; (8) there is need to satisfy all demands of a distribution and a factory; (9) Products are produced in a factory as a linear, also raw materials are produced in a supplier as a linear. Fig. 1 shows an illustration of three-echelon supply chain. 


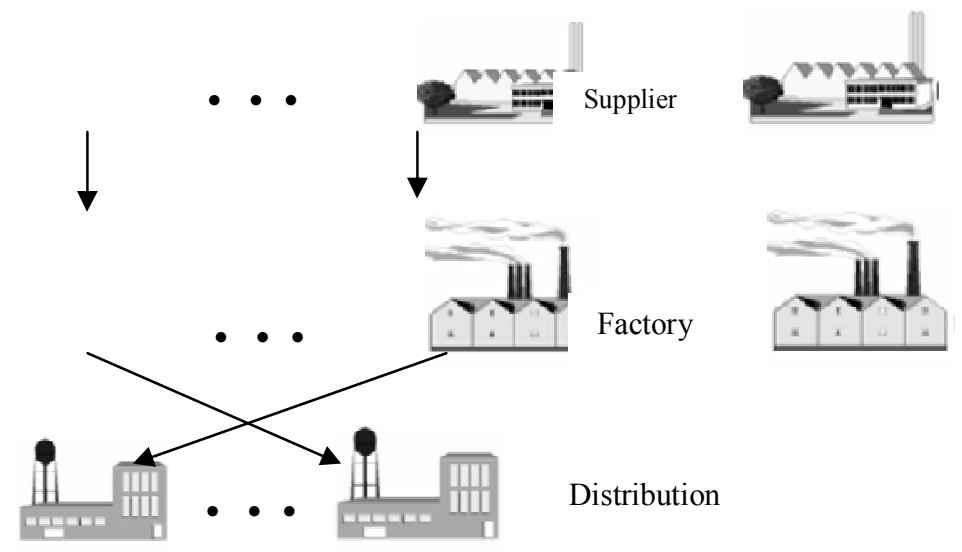

Fig. 1. An illustration of three-echelon supply chain

The objective functions and constraints are as follows:

$$
\begin{array}{ll}
\min F_{1}=\sum_{i=1}^{n} f_{i} y_{i}+\sum_{i=1}^{n} S_{i} V_{i}+\sum_{k=1}^{K} R_{k} U_{k}+\sum_{i=1}^{n} a_{i} G_{i}+\sum_{i=1}^{n} \sum_{j=1}^{m} C_{i j} z_{i j} D_{j}+\sum_{k=1}^{K} \sum_{i=1}^{n} B_{k i} x_{k i} Q_{i} \\
\min F_{2}=\sum_{i=1}^{n}\left(Q_{i}\left(Q_{i}+1\right) / 2\right) \times T_{i}+\sum_{k=1}^{K}\left(U_{k}\left(U_{k}+1\right) / 2\right) \times L_{k} \\
\sum_{k=1}^{K} x_{k i}=1 & i=1,2, \ldots, n \\
\sum_{i=1}^{n} z_{i j}=1 & j=1,2, \ldots, m \\
x_{k i} \leq y_{i} & k=1,2, \ldots, K, i=1,2, \ldots, n \\
z_{i j} \leq y_{i} & i=1,2, \ldots, n, j=1,2, \ldots, m \\
Q_{i}=\sum_{j=1}^{m} z_{i j} D_{j} & i=1,2, \ldots, n \\
U_{k}=\sum_{i=1}^{n} x_{k i} Q_{i} & k=1,2, \ldots, K \\
G_{i}=\max _{i}\left\{, Q_{i}-S_{i}\right\} & i=1,2, \ldots, n \\
\sum_{i=1}^{n} y_{i} \geq 1 & \\
x_{k i} \in\{0,1\} & i=1,2, \ldots, n, k=1,2, \ldots, K \\
y_{i} \in\{0,1\} & i=1,2, \ldots, n \\
z_{i j} \in\{0,1\} &
\end{array}
$$

The objective function (1) minimizes total cost of SC. Note that it is the sum of the factory setup, the production cost, the transportation cost and overtime cost. The objective function (2) is minimum total production time in factories and suppliers. Constraint (3) specifies that a factory can be served by only one supplier. Constraint (4) specifies that a distribution can be served by only one factory. Constraint 
(5) states that if a factory was set up, supplier do not deliver raw material from the site. Constraint (6) states that if a factory was set up, distributors do not send product to the site. Constraint (7) specifies the amount of produced per factory. Also, constraint (8) specifies the amount of produced per supplier. Constraint (9) will determine the amount of product that should be in excess of factory capacity to produce. Constraints (10) specifies that at least one factory should be set up to meet demand distributors. Finally, Constraints (11), (12) and (13) are specified type of decision variables.

\section{3- Solution method}

In this paper, a LA programming model is proposed in the supply chain of three echelon. The LA problems in large sizes are considered as the complicated and difficult ones, exact solution methods for solving them are usually time-consuming $[4,12]$. Hence, in this article come from a metaheuristic method called genetic algorithm is used. Genetic algorithm is a stochastic optimization method for solving difficult optimization problems is very useful [13, 14]. In 1975, genetic algorithm were first expressed by Holland [15]. In 2003, Zhou and Liu [16] using genetic algorithms to solve the problem of capacity locations. In 2012, Zarrinpoor and et al. [1] to solve the maximal covering locationallocation problem with genetic algorithm in the competitive and user-choice environment.

\subsection{Procedure of genetic algorithm}

In This paper, the proposed genetic algorithm for nonlinear programming is presented according to the objectives and constraints. The proposed GA consist of making three decisions: how many and which factories should be set up, which factories should be served by which supplier and which distributions should be served by which factory.

First, the algorithm randomly generates the initial generation of chromosomes. This proposed chromosome consists of three parts. P1, parent population is produced in each generation. P2 and P3, respectively, the population of children that come from crossing and mutation. Then, the algorithm calculates the fitness function and operators runs for each population. As far as the stop condition is achieved. If stopping conditions are not achieved, the algorithm deals with the mechanism chosen to produce a new generation. The flowchart of the proposed algorithms is presented in Fig. 2.

\subsection{Chromosome structure}

The first step in this proposed algorithm, Set of parameters is encoded as a gene [2]. Then connected them together to create a series of chromosomes. Each chromosome is made by three set of genes, the binary code of $x_{k i}, y_{i}$ and $z_{i j}$ that each of three genes in the initial generation randomly arise. These genes must to satisfy constraints 3 until 6 . Fig. 3 shows an illustration of a chromosome with $K=1, n$ $=2$ and $\mathrm{m}=1$. 


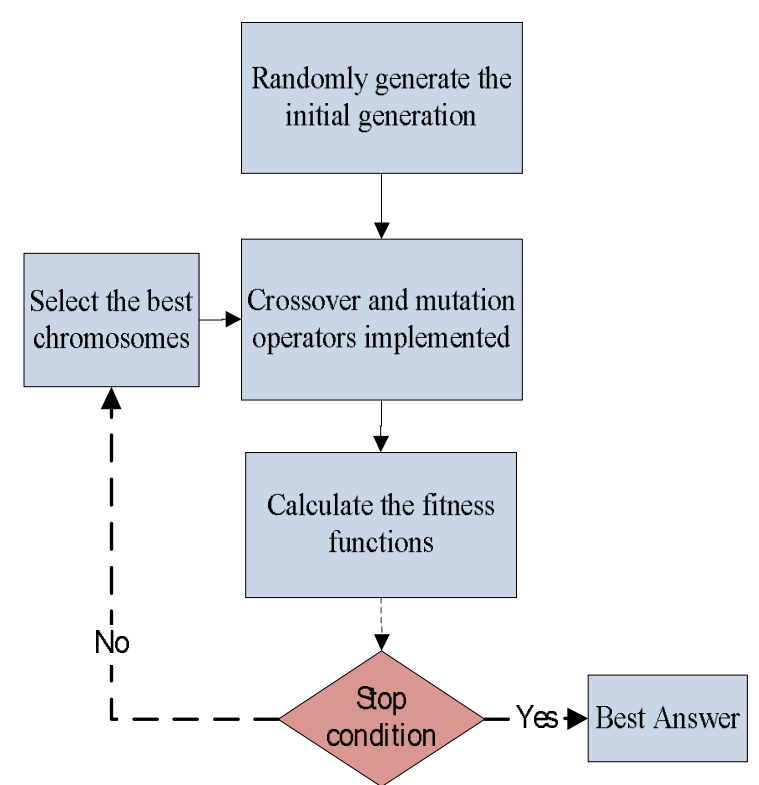

Fig. 2. The flowchart of the proposed algorithms

\begin{tabular}{|c|c|c|c|c|c|}
$\mathrm{X}(11)$ & $\mathrm{X}(12)$ & $\mathrm{y}(1)$ & $\mathrm{y}(2)$ & $\mathrm{Z}(11)$ & $\mathrm{Z}(21)$ \\
\hline 1 & 0 & 1 & 0 & 1 & 0 \\
\hline
\end{tabular}

Fig. 3. illustration of a chromosome

\subsection{Initial generation}

At this stage, the number of chromosomes (nPOP) are randomly generated and stored in P1.

\subsection{Fitness function}

Mathematical model presented in this paper has two objective functions that must be minimized. Therefore, the LP-metric method has been used in this model. In this method, each objective function to be optimized separately and then the distance between objective and model is minimizing [17]. Fitness function is based on LP-metric method as follows:

$$
F=\sqrt{\begin{array}{l}
\left(E \times\left(\left(\sum_{i=1}^{n} f_{i} y_{i}+\sum_{i=1}^{n} S_{i} V_{i}+\sum_{k=1}^{K} R_{k} U_{k}+\sum_{i=1}^{n} a_{i} G_{i}\right.\right.\right. \\
\left.\left.\left.+\sum_{i=1}^{n} \sum_{j=1}^{m} C_{i j} z_{i j} D_{j}+\sum_{k=1}^{K} \sum_{i=1}^{n} B_{k i} x_{k i} Q_{i}-F_{1}^{*}\right) / F_{1}^{*}\right)\right)^{2} \\
+\left((1-E) \times\left(\left(\sum_{i=1}^{n}\left(Q_{i}\left(Q_{i}+1\right) / 2\right) \times T_{i}\right.\right.\right. \\
\left.\left.\left.+\sum_{k=1}^{K}\left(U_{k}\left(U_{k}+1\right) / 2\right) \times L_{k}-F_{2}^{*}\right) / F_{2}^{*}\right)\right)^{2}
\end{array}}
$$

where $E$ is a value that is given to decision maker on priorities. 


\subsection{Crossover operator}

One-point crossover operation is used to the proposed GA for every three parts of chromosome. First, one random number between 1 and $n-1$ ( $\mathrm{n}$ is number of site $i$ ) is selected and employed as crossover cutting point for every three parts of chromosome, Because all three parts of the chromosome is the number of factory sites $(n)$. Then, two chromosome are selected from P1 and their corresponding parts of chromosome are exchanged. The chromosomes after crossover are repaired to commit the constraints 3 until 6. The number of chromosomes resulting from crossover in P2 are stored. The procedure of crossover could be illustrated in Fig. 4.

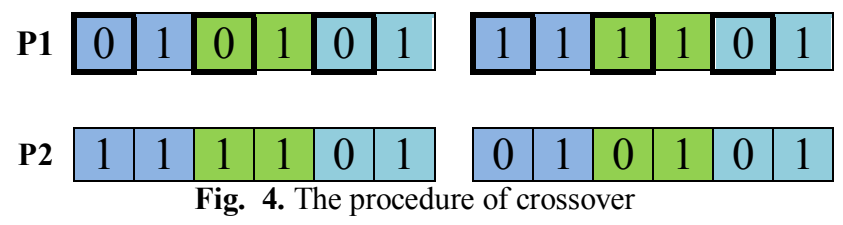

\subsection{Mutation operator}

Random mutation operation is used to the proposed GA. First, one random number between 1 and $\mathrm{n}$ (n is number of site $i$ ) is selected and employed as mutant gene for second part $\left(y_{i}\right)$ of chromosome. Then, one chromosome is selected from P1 and its corresponding part $\left(y_{i}\right)$ of chromosome is exchanged. Two other parts of chromosome after change are repaired to commit the constraints 3 until 6. The number of chromosomes resulting from mutation in P3 are stored. The procedure of mutation could be illustrated in Fig. 5 .

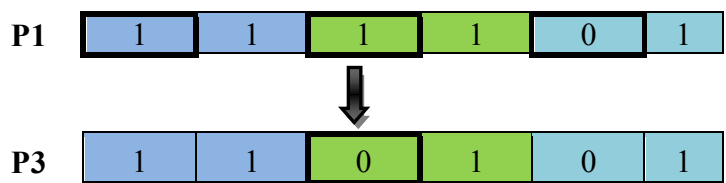

Fig. 5. The procedure of mutation

\subsection{Selection mechanism}

Selection mechanism is based on selection the best chromosomes in each generation. Chromosomes within the P1, P2 and P3 are merged and the fitness function are arranged from lowest to highest. Then, the population of chromosomes with the lowest fitness function for the next initial generation are selected. The scheme of selection mechanism is shown in Fig. 6.
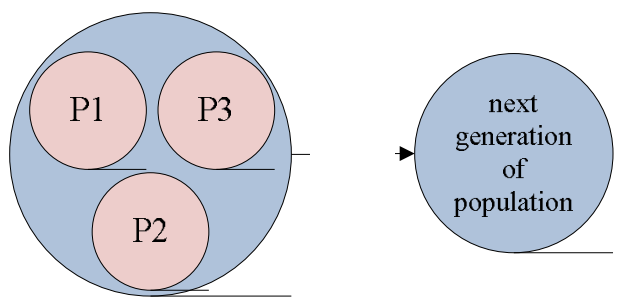

Fig. 6. The scheme of selection mechanism

\subsection{Stop condition}

In this algorithm, is achieved stopped if the number of generations is 100 or better is not done. 


\subsection{Parameter setting}

Genetic algorithm parameters (nPOP: number of population, Pcr: crossover rate and Pmu: mutation rate) are specified by RSM method. For setting the parameters of the RSM method has been used in Minitab14 program that size of problem under investigation is of 6 suppliers, 6 factories and distributions. Solutions optimized parameters of the algorithm is shown in Table 1. All the rest of parameters are shown in Appendix.

Table 1. The optimized parameter

\begin{tabular}{|c|ccc|}
\hline Optimal & nPOP & Pcr & Pmu \\
\hline High & 100 & 0.01 & 0.8 \\
Current & $\mathbf{2 0 0}$ & $\mathbf{0 . 1}$ & $\mathbf{0 . 9 2}$ \\
Low & 300 & 0.1 & 1 \\
\hline
\end{tabular}

\section{Computational results}

In this paper, computational results of the genetic algorithm is compared with the output Lingo 12 software. The proposed genetic algorithm has been implemented in Matlab software for the LA problem in three-echelon supply chain. These comparisons in Table 2 is shown.

As shown in Table 2, when the problem scale grows to 2 suppliers, 2 factories and 2 distributions, Lingo software is not able to find the optimum solution. But the genetic algorithm proposed in appropriate time obtains an acceptable answer.

Table 2. The computational results

\begin{tabular}{c|c|c|c|c|c|c}
\hline \multicolumn{3}{c|}{ Problem } & \multicolumn{2}{c|}{ Lingo 12 } & \multicolumn{2}{c}{ GA } \\
\hline K & $\mathbf{n}$ & $\mathbf{M}$ & $\begin{array}{c}\text { Fitness } \\
\text { function }\end{array}$ & $\begin{array}{c}\text { CPU } \\
\text { time (s) }\end{array}$ & $\begin{array}{c}\text { Fitness } \\
\text { Function }\end{array}$ & $\begin{array}{c}\text { CPU } \\
\text { time (s) }\end{array}$ \\
\hline 2 & 2 & 2 & 0.1613 & 1 & 0.1613 & 1.1561 \\
3 & 3 & 3 & 0.2306 & 1 & 0.2306 & 1.5862 \\
6 & 6 & 6 & - & - & 0.2621 & 1.8952 \\
7 & 7 & 7 & - & - & 0.3123 & 2.3542 \\
8 & 8 & 8 & - & - & 0.4123 & 4.2354 \\
9 & 9 & 9 & - & - & 0.5602 & 5.2145
\end{tabular}

\section{Conclusions}

In this paper, a LA model for minimizing the cost and time was used in the three-echelon supply chain. The proposed model includes three levels of suppliers, factories and distributors in the supply chain. In this paper has been effort that locate a number of factories among a finite set of sites, and the effort to allocate task assignment between suppliers, factories and distributions. First, the model used to solve the lingo 12 , but considering high complexity and nonlinear problems, this software is only able to resolving small-size model. Then in large size, was used to achieve a solution of a method metaheuristic called genetic algorithm. And compare the results of genetic algorithm with output lingo 12 software showed that the proposed genetic algorithm is capable of good performance. 
This research can be extended as follows: First, periodical demand could and Several product could be considered in the model. Second, other objectives, such as profit and inventory could be considered in the model. Finally, Costs such as purchase, orders and maintenance could be considered.

\begin{tabular}{l|l} 
Appendix. Parameters setting & \multicolumn{1}{c}{ Parameters } \\
\hline \multicolumn{1}{c}{ Value } \\
\hline $\begin{array}{l}\text { the fixed cost of setting up a factory at } \\
\text { site i (in thousands) }\end{array}$ & $\mathrm{f}_{i} \sim U(100000,200000)$ \\
\hline $\begin{array}{l}\text { capacity of factory located at site i (in } \\
\text { piece) }\end{array}$ & $S_{i} \sim U(500,700)$ \\
\hline $\begin{array}{l}\text { demand of distribution j (in piece) } \\
\text { Production cost per unit product } \\
\text { produced factory i (in } \\
\text { thousands/piece) }\end{array}$ & $D_{j} \sim U(600,800)$ \\
\hline $\begin{array}{l}\text { Production cost per unit raw material } \\
\text { in supplier k (in thousands/piece) }\end{array}$ & $V_{i} \sim U(150,200)$ \\
\hline $\begin{array}{l}\text { Production cost per unit product in } \\
\text { excess of factory i capacity (in } \\
\text { thousands/piece) }\end{array}$ & $R_{i} \sim U(50,80)$ \\
\hline $\begin{array}{l}\text { production time per unit of product } \\
\text { produced in factory I (in hours /piece) }\end{array}$ & $T_{i} \sim U(0.75,1.25)$ \\
\hline $\begin{array}{l}\text { production time per unit of raw } \\
\text { material produced in supplier k (in } \\
\text { hours/piece) }\end{array}$ & $L_{k} \sim U(0.5,0.75)$ \\
\hline $\begin{array}{l}\text { transportation cost per unit distributed } \\
\text { from factory i to distribution j (in } \\
\text { thousands/piece) }\end{array}$ & $C_{i j} \sim U(10,20)$ \\
\hline $\begin{array}{l}\text { transportation cost per unit delivered } \\
\text { from supplier k to factory i (in } \\
\text { thousands/piece) }\end{array}$ & $B_{k i} \sim U(5,10)$ \\
\hline
\end{tabular}

\section{References}

[1] Zarrinpour, N., Shavandi, H., \& Bagherinejad, J., "Extension of the Maximal Covering LocationAllocation Model for Congested System in the Competitive and User-choice Environment", International Journal of Industrial Engineering \& Production Management, Vol. 22, No. 4, pp. 393 404, 2012.

[2] Jabalameli, M. S, Shahanaghi, K., Hosnavi, R., \& Nasiri, M. R., "A Combined Model for Locating Critical Centers (HAPIT)", International Journal of Industrial Engineering \& Production Management, Vol. 20, No. 4, pp. 65-76, 2010.

[3] Weber, A., "Über den Standort der Industrien”. Tübingen, 1909. Alferd Weber's theory of the Location of Industries, University of Chicago Press (English translation by C.J. Friedrich, 1929).

[4] Cooper, L., "Location-allocation problems", Operational Research, Vol. 11, No. 3, pp. 331-343, 1963.

[5] Murtagh, B.A., \& Niwattisyawong, S.R., "Efficient method for the multi-depot location-allocation problem", Journal of the Operational Research Society, Vol. 33, N0. 7, pp. 629-634, 1982.

[6] Liu, C-M., Kao, R-L., \& Wang, A-H., "Solving location-allocation problems with rectilinear distances by simulated annealing", Journal of Operational Research, Vol. 45, No. 11, pp. 1304$1315,1994$.

[7] Zhou, J., \& Liu, B., "New stochastic models for capacitated location-allocation problem", Computers \& Industrial Engineering, Vol. 45, No. 1, pp. 111-125, 2003. 
[8] Bischoff, M., \& Dächert, K., “Allocation search methods for generalized class of locationallocation problems", European Journal of Operational Research, Vol. 192, No. 3, pp. 793-807, 2009.

[9] Stadtler, H., \& Kilger, C., "Supply chain management and advanced planning", Springer, 2000.

[10] Ho, W., Lee, C. K. M., \& Ho, G. T. S., "Optimization of the facility location-allocation problem in a customer-driven supply chain", Operations Management Research, Vol. 1, pp. 69-79, 2008.

[11] Wang, K.-J., Makond, B., \& Liu, S.-Y., "Location and allocation decisions in a two-echelon supply chain with stochastic demand - A genetic-algorithm based solution", Expert Systems with Applications, Vol. 38, pp. 6125-6131, 2011.

[12] Taghavifard, M. T., \& Shahsavari, A., "Multi-Objective Location-Allocation Problems Using Simulated Annealing", International Journal of Industrial Engineering \& Production Management, Vol. 19, No. 4, pp. 93-105, 2009.

[13] Beasley, D., Bull, D. R., \& Martin, R. R., "An overview of genetic algorithms: part 1, fundamentals", University Comput, Vol. 15, No. 2, pp. 58-69, 1993.

[14] Renner, G., \& Ekart, A., "Genetic algorithms in computer aided design", Computer-Aided Design, Vol. 35, No. 8, pp. 709-726, 2003.

[15] Holland, J. H., "Adaptation in natural and artificial systems", Ann Abor, MI: University of Michigan Press, 1975.

[16] Zhou, J., \& Liu, B., "New stochastic models for capacitated location-allocation problem", Computers \& Industrial Engineering, Vol. 45, No. 1, pp. 111-125, 2003.

[17] Taylor, D., "Global Cases in Logistics and Supply Chain Management", Industrial Thompson Business, Boston, 1997. 